\title{
Composição Química e Digestibilidade In Vitro do Feno de Brachiaria decumbens Stapf. Tratado com Uréia ${ }^{1}$
}

\section{Kátia Fernanda Gobbi ${ }^{2}$, Rasmo Garcia ${ }^{3}$, Américo Fróes Garcez Neto ${ }^{2}$, Odilon Gomes Pereira ${ }^{3}$, Fernando Salgado Bernardino ${ }^{2}$, Fernanda Cipriano Rocha ${ }^{2}$}

RESUMO - Avaliaram-se os efeitos da adição de uréia em níveis crescentes sobre a composição química e digestibilidade in vitro da matéria seca (DIVMS) do feno de Brachiaria decumbens colhida no estádio de pós-florescimento. O feno foi tratado com seis níveis de uréia $(0,2,4,6,8$ e 10\%), com base na matéria seca (MS). A uréia foi dissolvida em quantidade de água suficiente para elevar o teor de umidade do feno para $30 \%$. O delineamento experimental adotado foi o inteiramente casualizado, com três repetições. O feno tratado foi armazenado em sacos plásticos ( $2 \mathrm{~kg} / \mathrm{saco})$ vedados, por 35 dias, e, após abertura, foram coletadas amostras para as análises químicas. Verificou-se que o teor de nitrogênio total (NT) aumentou linearmente em função dos níveis crescentes de uréia. Os teores de NIDN e NIDA, em relação ao nitrogênio total (NIDN/NT e NIDA/NT), tiveram redução linear em função dos níveis crescentes de uréia, demonstrando aumento nos teores de nitrogênio disponível no material amonizado. A adição de uréia promoveu redução no teor de fibra em detergente neutro (FDN), fibra em detergente ácido (FDA) e celulose. Os teores de hemicelulose e lignina não foram alterados pelo tratamento com uréia. A digestibilidade in vitro da matéria seca (DIVMS) foi influenciada de forma quadrática pelos níveis de uréia, estimando-se valor máximo de $68,9 \%$ para o nível de 7,15\% de uréia. A amonização com uréia alterou a composição química e a digestibilidade do feno de Brachiaria decumbens, melhorando o valor nutritivo do material tratado.

Palavras-chave: amonização, NIDA, NIDN, nitrogênio total, parede celular

\section{Chemical Composition and In Vitro Digestibility of Brachiaria decumbens Stapf. Hay Treated with Urea}

\begin{abstract}
An experiment was conducted to evaluate the effects of urea treatment on the chemical-bromatologic compounds and in vitro dry matter digestibility (IVDMD) of Brachiaria decumbens hay. The hay were reconstituted with water to get final forage moisture concentration of $30 \%$, and treated with urea at $0,2,4,6,8$, and $10 \%$ of the forage dry matter. A completely randomized design with three replicates was used. The material was stored in plastic bags ( $2 \mathrm{~kg} /$ plastic bag) for 35 days, and after plastic bag opening, samples were collected to chemical analysis. Hay total nitrogen (TN) concentration increased linearly with increasing urea level. The NDIN/TN and ADIN/TN ratios decreased with increasing urea level. The neutral detergent fiber (NDF), acid detergent fiber (ADF) and cellulose contents decreased due to ammoniation with urea. The hemicellulose and lignin contents were no affected with urea treatment. The in vitro dry matter digestibility (IVDMD) had a quadratic response to the increasing urea level reaching the maximum digestibility of $68.9 \%$ at the $7.15 \%$ urea level. Urea ammoniation altered the chemical composition and digestibility of the Brachiaria decumbens hay, improving the nutritive value of forage.
\end{abstract}

Key Words: ADIN, ammoniation, cell wall, NDIN, total nitrogen

\section{Introdução}

A maior parte do território brasileiro caracteriza-se por duas estações (chuvosa e seca) bem definidas, o que implica na estacionalidade da produção de forragens.

A alta produção de forrageiras no período chuvoso muitas vezes é subutilizada e parte acaba sendo perdida, enquanto, no período seco do ano, ocorre escassez de forragem para alimentação dos rebanhos. No entanto, para que os animais mantenham bons níveis de produção ao longo do ano, é necessário o uso de volumosos de qualidade também no período seco, uma vez que as exigências nutricionais dos animais permanecem as mesmas durante todo ano.

A fenação pode ser boa opção para o aproveitamento do excesso de forragem produzida no período chuvoso. No entanto, encontra-se como obstáculo a adequação do estádio de desenvolvimento ideal da forrageira, ou seja, a produção máxima com elevado valor nutritivo, às condições apropriadas para rápida desidratação do material (Burns, 1978; Seiffert, 1988). Com o intuito de contornar os problemas climáticos que

\footnotetext{
${ }^{1}$ Parte da dissertação de Mestrado da primeira autora apresentada à UFV.

2 Estudante de Doutorado, Departamento de Zootecnia/UFV. E.mail: kfgobbi@vicosa.ufv.br

${ }^{3}$ Professor do Departamento de Zootecnia/UFV. E.mail: rgarcia@ufv.br
} 
limitam os processos de conservação, muitas vezes, opta-se pelo corte da forrageira no período de outono, quando diminui o risco de chuvas. Entretanto, nesta época do ano, geralmente ocorre queda acentuada no valor nutritivo das gramíneas forrageiras tropicais, em decorrência do florescimento (Reis et al., 2002).

Os fenos produzidos a partir de gramíneas de clima tropical colhidas no estádio de pós-florescimento e as palhadas obtidas após a colheita de grãos de cereais e sementes de gramíneas forrageiras são alimentos essencialmente energéticos, de baixos teores protéico e mineral, pouca digestibilidade e baixo consumo voluntário (Garcia \& Pires, 1998).

Apesar de esses produtos serem considerados uma alternativa para a alimentação dos rebanhos no período de escassez de forragem, possuem características que limitam seu aproveitamento pelos animais, destacando-se o elevado conteúdo de parede celular, alto teor de fibra em detergente ácido (FDA) e lignina, a pequena disponibilidade de compostos nitrogenados e baixa digestibilidade da matéria seca (Reis \& Rodrigues, 1993). Para que esses volumosos de baixa qualidade possam ser utilizados de forma eficiente na alimentação de ruminantes, deve-se buscar alternativas que permitam aumentar seu valor nutritivo e seu aproveitamento pelos animais, de modo que sejam minimizados esses problemas.

Nos últimos anos, têm-se utilizado diversos tipos de tratamentos químicos, físicos e biológicos visando melhorar as características desses volumosos para que possam ser melhor aproveitados pelos ruminantes.

Entre as diferentes alternativas para o tratamento químico de volumosos, a amonização, utilizando-se uréia como fonte de amônia, vem promovendo resultados bastante satisfatórios (Brown \& Adjei, 1995; Rosa et al., 1998; Cândido et al., 1999; Reis et al., 2001a,b,c; Granzin \& Dryden, 2003. O uso da uréia para o tratamento químico de volumosos é uma alternativa viável, por ser um produto com grande disponibilidade no mercado, de fácil aplicação e menos perigoso à intoxicação humana e, na maioria das vezes, menos oneroso que a amônia anidra.

Diversas pesquisas têm indicado que o tratamento de volumosos de baixa qualidade, utilizando-se fontes de amônia, pode melhorar a qualidade desses produtos, elevando significativamente seu valor nutritivo e, conseqüentemente, seu consumo e aproveitamento pelos animais (Brown \& Adjei, 1995; Reis et al., 2001a,b,c; Granzin \& Dryden, 2003 ). No entanto, os resultados obtidos nessas pesquisas são bastante variáveis.
Conduziu-se esse experimento objetivando-se avaliar a composição química e a digestibilidade in vitro do feno de Brachiaria decumbens tratado com diferentes níveis de uréia.

\section{Material e Métodos}

O experimento foi conduzido nas dependências do Departamento de Zootecnia da Universidade Federal de Viçosa (UFV), em Viçosa-MG, no período de 12 de dezembro de 2002 a 16 de janeiro de 2003. As análises laboratoriais foram realizadas nos Laboratórios de Nutrição Animal e de Forragicultura do Departamento de Zootecnia da UFV.

O feno utilizado foi o de Brachiaria decumbens, colhida no estádio de pós-florescimento e tratado com os seguintes níveis de uréia: 0 (controle), 2, 4, 6, 8 e $10 \%$ na matéria seca.

$\mathrm{O}$ delineamento experimental adotado foi o inteiramente casualizado, com seis tratamentos e três repetições.

O feno tratado ou não com uréia foi acondicionado em sacos plásticos transparentes, etiquetados e vedados com fita adesiva, para impedir a saída da amônia produzida, que foram armazenados em galpão coberto durante 35 dias.

As quantidades de uréia utilizadas para amonização do feno foram calculadas de acordo com a quantidade de feno a ser tratado $(2 \mathrm{~kg}$ feno/ saco) e com o teor de matéria seca do material (89\%). A uréia foi dissolvida em quantidade de água suficiente para elevar o teor de umidade do feno para $30 \%$ e distribuída sobre as camadas de feno, dentro dos sacos, com auxílio de um regador.

Após a abertura, os sacos foram submetidos à aeração, por 24 horas, para que a amônia que não reagiu com o material fosse eliminada.

A coleta de amostras de cada tratamento foi feita após a homogeneização do material contido em cada saco. As amostras foram acondicionadas em sacos plásticos e armazenadas em congelador, de modo que aquelas utilizadas nas análises químicas não sofreram pré-secagem em estufa, evitando-se, assim, a perda de nitrogênio. Foram colocadas em sacos plásticos, congeladas em nitrogênio líquido e imediatamente processadas em moinho com peneira de $1 \mathrm{~mm}$. As amostras moídas foram acondicionadas em recipientes com tampa, etiquetados e armazenados em geladeira. 
Foram determinados os teores de matéria seca (MS), nitrogênio total (NT), fibra em detergente neutro (FDN), fibra em detergente ácido (FDA), lignina, hemicelulose, celulose, nitrogênio insolúvel em detergente ácido (NIDA) e nitrogênio insolúvel em detergente neutro (NIDN) e a digestibilidade in vitro da matéria seca, segundo metodologias descritas por Silva \& Queiroz (2002).

Os resultados obtidos foram interpretados estatisticamente por meio de análises de variância e de regressão. Os modelos que melhor explicaram o comportamento das variáveis foram escolhidos com base no coeficiente de determinação ajustado, pela significância da regressão e da falta de ajustamento, testados pelo teste $\mathrm{F}$, e pela significância dos coeficientes de regressão, testada pelo teste $\mathrm{T}$, adotando-se nível de significância aceitável de até $1 \%$ de probabilidade.

As análises estatísticas foram realizadas utilizando-se os procedimentos de modelos lineares gerais (GLM) e de regressão (REG), por intermédio do Sistema de Análises Estatísticas SAS (1990).

\section{Resultados e Discussão}

Os teores percentuais médios de nitrogênio total (NT), nitrogênio insolúvel em detergente neutro (NIDN), nitrogênio insolúvel em detergente ácido (NIDA) e NIDN e NIDA, em relação ao nitrogênio total (NIDN/ NT e NIDA/NT), do feno de capim-braquiária tratado com diferentes níveis de uréia, juntamente com suas equações de regressão e coeficientes de determinação, são apresentados na Tabela 1.
$\mathrm{O}$ teor de nitrogênio total do feno cresceu linearmente $(\mathrm{P}<0,001)$ com a elevação dos níveis de uréia (Tabela 1), o que pode ser explicado pelo fato de terse adicionado ao feno níveis crescentes de nitrogênio não-protéico (NNP). Aumentos nos teores de NT para níveis crescentes de uréia também foram encontrados nos trabalhos realizados por Brown \& Adjei (1995), Cândido et al. (1999) e Granzin \& Dryden (2003), com feno de capim-colonião, bagaço de cana e capim-de-rhodes, respectivamente.

É importante considerar que o teor de NT do feno não-tratado com uréia é baixo $(0,87 \%)$, sendo considerado inadequado para suprir os requerimentos nutricionais dos ruminantes em produção (Van Soest et al., 1984). Portanto, o tratamento do feno com uréia e o conseqüente aumento no teor de NT podem contribuir para suprir esta necessidade de nitrogênio para síntese microbiana e/ou reduzir a necessidade de uma fonte suplementar de nitrogênio para o rebanho.

Foi observado efeito $(\mathrm{P}<0,001)$ dos níveis de uréia sobre os teores de nitrogênio insolúvel em detergente neutro (NIDN), cujos dados ajustaram-se a um modelo quadrático (Tabela 1), estimando-se valor máximo de $0,56 \%$, para fenos tratados com $6,67 \%$ de uréia. Constata-se, pois, que a aplicação de uréia pode aumentar a retenção de nitrogênio na parede celular. Por outro lado, houve efeito de níveis de uréia sobre o teor de NIDA, registrando-se valor médio de $0,24 \%$.

Granzin \& Dryden (2003), utilizando capim-derhodes tratado com $0,2,4,6$ e $8 \%$ de uréia com base na MS, também não verificaram efeito da uréia sobre

Tabela 1 - Valores médios de nitrogênio total (NT), nitrogênio insolúvel em detergente neutro (NIDN) e em detergente ácido (NIDA) e NIDN e NIDA em relação ao nitrogênio total (NIDN/NT e NIDA/NT), no feno de Brachiaria decumbens tratado com uréia

Table 1 - Average values of total nitrogen (TN), neutral detergent insoluble nitrogen (NDIN), acid detergent insoluble nitrogen (ADIN), NDIN and ADIN in relation to total nitrogen (NDIN/TN and ADIN/TN), in urea treated Brachiaria decumbens hay

\begin{tabular}{|c|c|c|c|c|c|c|c|}
\hline \multirow[t]{2}{*}{ Item } & \multicolumn{6}{|c|}{$\begin{array}{c}\text { Nível de uréia }(\%) \\
\text { Urea level }\end{array}$} & \multirow[t]{2}{*}{$\begin{array}{c}\text { Equação de regressão } \\
\text { Regression esquation }\end{array}$} \\
\hline & 0 & 2 & 4 & 6 & 8 & 10 & \\
\hline $\mathrm{NIDN}^{1}$ & 0,42 & 0,49 & 0,56 & 0,56 & 0,54 & 0,54 & $\hat{\mathrm{Y}}=0,4301+0,0387 * * * \mathrm{U}-0,0029 * * * \mathrm{U}^{2}\left(\mathrm{R}^{2}=0,93\right)$ \\
\hline $\mathrm{NIDA}^{1}$ & 0,21 & 0,23 & 0,25 & 0,26 & 0,26 & 0,22 & $\hat{\mathrm{Y}}=0,24$ \\
\hline NIDN/NT & 48,8 & 30,7 & 24,6 & 18,5 & 14,1 & 13,6 & $\hat{\mathrm{Y}}=41,6164-3,3153 * * * \mathrm{U}\left(\mathrm{r}^{2}=0,84\right)$ \\
\hline
\end{tabular}

1 Valores observados, expressos em \%MS (Observed values, in \%DM).

$* * *$ Significativo a $0,1 \%$ de probabilidade pelo teste $\mathrm{t}$ (Significant at .1\% by $t$ test). 
os teores de NIDA do capim, sugerindo que o nitrogênio dosado foi pouco retido na porção insolúvel em detergente ácido (celulose e lignina) ou, ainda, que ocorreu uma solubilização parcial destes compostos, sendo importante considerar que os compostos nitrogenados presentes na forma de NIDA são indisponíveis para os animais (Sniffen et al., 1992).

A relação NIDN/NT e NIDA/NT diminuiu $(\mathrm{P}<0,001)$ em resposta à amonização com uréia e os dados ajustaram-se a modelos lineares (Tabela 1).

Ao se estimar a quantidade de nitrogênio disponível (ND), correspondente à soma das frações A, B1 e B3 no sistema de avaliação de dietas para ruminantes, proposto por Fox et al. (1990), foram encontrados os valores médios de 0,$44 ; 1,13 ; 1,73 ; 2,43 ; 3,38$ e 3,49 para os níveis de $0 ; 2 ; 4 ; 6 ; 8$ e $10 \%$ de uréia, respectivamente. As frações A, B1 e B2 equivalem ao $\mathrm{N}_{-} \mathrm{NH}_{3}$, aos peptídeos e aminoácidos (A), à proteína verdadeira rapidamente degradada no rúmen $(\mathrm{B} 1)$ e à proteína verdadeira com velocidade média de degradação ruminal (B2). O aumento gradual no teor de ND em função dos níveis de uréia evidencia que a adição de nitrogênio não-protéico (NNP) promoveu diluição dos conteúdos de NIDN e NIDA em relação ao nitrogênio total (NT), acarretando aumento na disponibilidade de nitrogênio para os microorganismos ruminais.

Campos (1995), Reis et al. (1998, 2001c) e Souza et al. (2001) obtiveram resultados semelhantes, evidenciando os efeitos positivos da amonização sobre a fração nitrogenada dos volumosos tratados.

Os teores médios de fibra em detergente neutro (FDN), fibra em detergente ácido (FDA), hemicelulose, celulose e lignina do feno de capimbraquiária tratado com uréia e suas respectivas equações de regressão encontram-se na Tabela 2.

$\mathrm{O}$ teor de FDN do feno foi influenciado de forma quadrática $(\mathrm{P}<0,01)$ pelos níveis de uréia (Tabela 2$)$, estimando-se valor mínimo de $81,0 \%$ para o nível de $9,05 \%$ de uréia. Esta redução nos teores de FDN pode ser atribuída à solubilização parcial da fração hemicelulose da parede celular (Van Soest et al., 1984).

Reis et al. (2001b), Fernandes et al. (2002) e Granzin \& Dryden (2003), que trabalharam com amonização de fenos de gramíneas tropicais, feno de capim-braquiária e capim-de-rhodes, respectivamente, também observaram redução nos teores de FDN decorrente do tratamento dos volumosos com uréia.

Não houve efeito de níveis de uréia sobre os teores de hemicelulose, estimando-se valor médio de
$37,0 \%$. No entanto, boa parte dos estudos sobre a amonização de volumosos com uréia tem registrado diminuição nos teores dessa fração da parede celular (Brown \& Adjei, 1995; Rosa et al., 1998; Reis et al. 2001b). Este comportamento pode ser resultante do fato de a hemicelulose ter sido calculada a partir da diferença entre os teores de FDN e FDA, uma vez que as curvas de redução de FDN e FDA apresentaram comportamento diferenciado (quadrático e linear, respectivamente) em relação aos tratamentos com uréia.

Os teores de FDA e celulose reduziram linearmente $(\mathrm{P}<0,001)$ em função dos níveis de uréia (Tabela 2$)$, possivelmente pelo fato de que, quando materiais fibrosos são tratados com produtos alcalinos, como a uréia, as ligações intermoleculares, mais especificamente as pontes de hidrogênio, entre as moléculas de celulose se rompem, solubilizando parte deste componente da parede celular (Van Soest, 1994). Segundo Klopfenstein et al. (1978), a redução no conteúdo de FDA nos materiais amonizados está associada à solubilização de lignina e celulose, presumidamente como um resultado da redução da cristalinidade da celulose e também em razão de sua expansão e da saponificação das ligações éster entre lignina e hemicelulose.

Estes resultados corroboram os obtidos por Reddy et al. (1993), Hai \& Singh (1994) e Leal et al. (1994), que observaram redução nos teores de FDA de feno de sorgo, palhada de aveia e palhada de sorgo, respectivamente, tratados com fontes de amônia. Fahmy \& Klopfenstein (1994), Leal et al. (1994) e Shen et al. (1998) também relataram declínio no teor de celulose de volumosos amonizados.

A exemplo da hemicelulose, o teor de lignina não foi influenciado pelos níveis de uréia, registrando-se valor médio de 9,2\% (Tabela 2). Shen et al. (1998), Souza et al. (2001) e Reis et al. (2001b) também não detectaram efeito da amonização sobre o teor de lignina. No entanto, as respostas do teor de lignina de volumosos em relação à amonização é bastante variável e contraditória.

É importante considerar que as respostas à amonização de volumosos variam em função de diversos fatores, como conteúdo de umidade do material tratado e características químicas da planta (Van Soest, 1994).

A digestibilidade in vitro foi influenciada de forma quadrática $(\mathrm{P}<0,001)$ pelos níveis de uréia, estimando-se valor máximo de $68,9 \%$ para o nível de $7,15 \%$ de uréia, conforme a equação de regressão $\hat{\mathrm{Y}}=54,0025+4,1916 * * * \mathrm{U}-0,2931 * * * \mathrm{U}^{2}\left(\mathrm{r}^{2}=0,99\right)$ (Figura 1). 
Tabela 2 - Teores médios de fibra em detergente neutro (FDN), fibra em detergente ácido (FDA), hemicelulose (HEM), celulose (CEL) e lignina do feno de Brachiaria decumbens tratado com uréia

Table 2 - Average values of neutral detergent fiber (NDF), acid detergent fiber (ADF), hemicelullose (HEM), celullose (CEL) and lignin of urea treated Brachiaria decumbens hay

\begin{tabular}{|c|c|c|c|c|c|c|c|}
\hline \multirow[t]{2}{*}{ Item } & \multicolumn{6}{|c|}{$\begin{array}{c}\text { Nível de uréia (\%) } \\
\text { Urea level }\end{array}$} & \multirow[t]{2}{*}{$\begin{array}{c}\text { Equação de regressão } \\
\text { Regression esquation }\end{array}$} \\
\hline & 0 & 2 & 4 & 6 & 8 & 10 & \\
\hline $\mathrm{FDN}^{1}$ & 87,7 & 86,3 & 84,2 & 80,5 & 80,1 & 81,3 & $\hat{\mathrm{Y}}=88,4638-1,6381 * * * \mathrm{U}+0,0905^{*} * \mathrm{U}^{2}\left(\mathrm{R}^{2}=0,92\right)$ \\
\hline FDA $^{1}$ & 49,7 & 49,0 & 45,5 & 45,6 & 44,5 & 43,9 & $\hat{\mathrm{Y}}=49,4134-0,6096 * * * \mathrm{U}\left(\mathrm{r}^{2}=0,89\right)$ \\
\hline HEM $^{1}$ & 38,0 & 37,3 & 38,6 & 35,0 & 35,7 & 37,4 & $\hat{\mathrm{Y}}=37,0$ \\
\hline $\mathrm{CEL}^{1}$ & 38,4 & 38,2 & 36,1 & 35,5 & 35,0 & 34,6 & $\hat{\mathrm{Y}}=38,3777-0,4125 * * * \mathrm{U}\left(\mathrm{r}^{2}=0,91\right)$ \\
\hline Lignina $^{1}$ & 10,2 & 10,2 & 8,9 & 8,8 & 8,8 & 8,3 & $\hat{\mathrm{Y}}=9,2$ \\
\hline
\end{tabular}

1 Valores observados, expressos em \%MS (Observed values, in \%DM).

*** Significativo a $0,1 \%$ de probabilidade pelo teste $\mathrm{t}$ (Significant at $.1 \%$ by $t$ test).

** Significativo a $1 \%$ de probabilidade pelo teste $\mathrm{t}$ (Significant at $1 \%$ by $t$ test).

Aumentos na DIVMS de materiais amonizados se devem à ação da amônia sobre os constituintes da parede celular. A amônia pode agir sobre as moléculas de hemicelulose, promovendo o rompimento de ligações e a solubilização parcial deste componente, facilitando a ação dos microrganismos ruminais sobre a parede celular (Klopfenstein, 1978). Além disso, existe a possibilidade de a amônia promover o rompimento das pontes de hidrogênio entre as moléculas de celulose, promovendo sua solubilização parcial (Van Soest, 1994), e entre as moléculas de celulose e hemicelulose, permitindo hidratação mais rápida e eficiente da parede celular, facilitando o acesso dos microrganismos ruminais e aumentando a digestão (Berger et al., 1994).

Ressalta-se que, neste estudo, a amonização do feno promoveu uma solubilização parcial dos constituintes da parede celular, o que, provavelmente, resultou em incremento no conteúdo de carboidratos prontamente digestíveis (Van Soest, 1994). A amonização do feno também promoveu aumento no conteúdo de nitrogênio disponível, o que, por sua vez, também favoreceu a ação dos microrganismos ruminais, aumentando a digestibilidade do feno.

Para determinação da DIVMS do feno, utilizou-se a técnica proposta por Tilley \& Terry (1963), que considera como digerida a porção não recuperada após as etapas de fermentação e digestão com pepsina ácida. Portanto, é importante salientar que, neste estudo, não ocorreu solubilização significativa da lignina e que não se detectou a formação de produtos da reação de Maillard (o teor de NIDA não foi alterado), que seriam considerados como digeridos pela técnica da digestão in vitro, promovendo superestimativa dos valores de digestibilidade (Van Soest \& Mason, 1991).

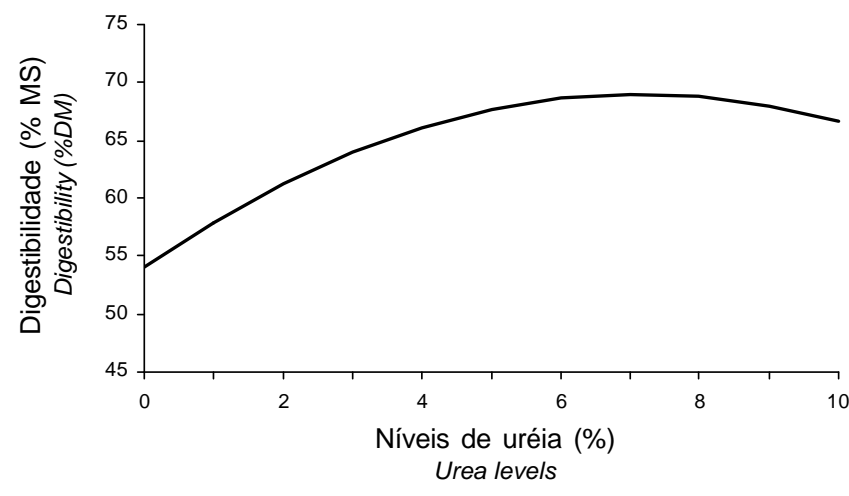

Figura 1 - Valores médios da digestibilidade in vitro da matéria seca (DIVMS) do feno de Brachiaria decumbens tratado com diferentes níveis de uréia.

Figure 1 - Average values of in vitro dry matter disappearence (IVDMD) of Brachiaria decumbens hay treated with different urea levels.

\section{Conclusões}

A amonização com uréia proporcionou melhoria no valor nutritivo do feno de capim-braquiária, o que pode ser comprovado pela elevação no teor de nitrogênio disponível e na DIVMS e pela redução dos conteúdos de FDN e FDA e das relações NIDN/NT e NIDA/NT.

Recomenda-se a adição de $7 \%$ de uréia (na base da MS), visto que esse nível proporcionou máxima digestibilidade in vitro da matéria seca. 


\section{Literatura Citada}

BERGER, L.L.; FAHEY JR., G.C.; BOURQUIM, L.O. et al. Modification of forage quality after harvest. In: FAHEY JR., G.C. et al. (Ed.). Forage quality, evaluation e etilization. Medison: American Society of Agronomy, 1994. p.922-966.

BROWN, W.F.; ADJEI, M.B. Urea ammoniation effects on the nutritive value of Guineagrass (Panicum maximum) hay. Journal Animal Science, v.73, p.3085-3093, 1995

BURNS, J.C. Balancing forage quality and quantity. In: Advances in hay, silage and pastures quality. Lexington: American Forage and Grassland Council, 1978. p.8-23.

CAMPOS, M.C.L. Níveis de amônia anidra e períodos de amonização sobre a composição químico-bromatológica e degradabilidade dos fenos de alfafa (Medicago sativa $L$.) e coast-cross (Cynodon dactylon (L.) Pers. Cv. Coastcross) com alta umidade. Viçosa, MG: Universidade Federal de Viçosa, 1995. 130p. Dissertação (Mestrado em Zootecnia) Universidade Federal de Viçosa, 1995.

CÂNDIDO, M.J.D.; NEIVA, J.N.M.; PIMENTEL, J.C.M. et al. Avaliação do valor nutritivo do bagaço de cana-de-açúcar amonizado com uréia. Revista Brasileira de Zootecnia, v.28, n.5, p.928-935, 1999.

FAHMY, S.T.M.; KLOPFENSTEIN, T.J. Treatment with different chemicals and their effects on the digestibility of maize stalks. 2. Intake and in vivo digestibility as affected by chemical treatment and monensin supplementation. Animal Feed Science and Technology, v.45, n.3/4, p. 309-316, 1994.

FERNANDES, L.O.; REIS, R.A.; RODRIGUES, L.R.A. et al. Qualidade do feno de Brachiaria decumbens Stapf. submetido ao tratamento com amônia anidra ou uréia. Revista Brasileira de Zootecnia, v.31, n.3, p. 1325-1332, 2002.

FOX, D.G.; SNIFFEN, C.J.; O'CONNOR, J.D. et al. The Cornell net carbohydrate and protein system for evaluating cattle diets. Search Agriculture. Ithaca: Cornell Univ. Agric. Exp. Stn. $\mathrm{n}^{\circ}$ 34., 1990.

GARCIA, R.; PIRES, A.J.V. Tratamento de volumosos de baixa qualidade para utilização na alimentação de ruminantes. In: CONGRESSO NACIONAL DOS ESTUDANTES DE ZOOTECNIA, 1998, Viçosa, MG. Anais... Viçosa, MG: Associação Mineira dos Estudantes de Zootecnia, 1998. p.33-61.

GRANZIN, B.C.; DRYDEN, G.McL. Effects of alkalis, oxidants and urea on the nutritive value of rhodes grass (Chloris gayana cv. Callide). Animal Feed Science and Technology, v.103, p.113-122, 2003.

HAI, N.V.; SINGH, G.P. Effect of ammoniation through urea treatment of oat straw on the rumen degradability of fibre. Indian Journal of Dairy Science, v.47, n.3, p.176-180, 1994.

KLOPFENSTEIN, T.J. Chemical treatment of crop residues. Journal Animal Science, v.46, n.3, p.841-848, 1978.

LEAL, M.; SHIMADA, A.; HERNÁNDEZ, E. The effect of $\mathrm{NH}_{3}$ and/or $\mathrm{SO}_{2}$ on the compositional and histological characteristics of sorghum stover. Animal Feed Science and Technology, v.47, p.141-150, 1994.

REDDY, D.V.; RAMACHANDRA REDDY, R.; SUBRA REDDY, K.V. Effect of urea-ammoniation of moist sorghum hay chemical composition and degradation kinetics. Indian Journal of Dairy Science, v.10, n.1, p.45-48, 1993.

REIS, R.A.; RODRIGUES, L.R.A. Amonização de volumosos. Jaboticabal: FCAVJ-UNESP/FUNEP, 1993.
REIS, R. A.; RODRIGUES, L.R.A.; PEREIRA, J.R.A. et al. Composição química e digestibilidade de fenos tratados com amônia anidra ou uréia. Revista Brasileira de Zootecnia, v.30, n.3, p.666-673, 2001a.

REIS, R. A.; RODRIGUES, L.R.A.; RESENDE, K.T. et al. Avaliação de fontes de amônia para o tratamento de fenos de gramíneas tropicais. 1. Constituintes da parede celular, poder tampão e atividade ureática. Revista Brasileira de Zootecnia, v.30, n.3, p.674-681, 2001 b.

REIS, R.A.; RODRIGUES, L.R.A.; RESENDE, K.T. et al. Avaliação de fontes de amônia para o tratamento de fenos de gramíneas tropicais. 2. Compostos nitrogenados. Revista Brasileira de Zootecnia, v.30, n.3, p.682-686, 2001c.

REIS, R.A.; RODRIGUES, L.R.A.; RIGGIERI, A.C. et al. Avaliação de fontes de amônia para o tratamento de fenos de gramíneas tropicais. In: REUNIÃO ANUAL DA SOCIEDADE BRASILEIRA DE ZOOTECNIA, 35., 1998, Botucatu. Anais... Botucatu: Sociedade Brasileira de Zootecnia, 1998b. p.563-565.

REIS, R.A.; ROSA, B.; MOREIRA, A.L. Tratamento químico de volumosos: amonização. In: SIMPÓSIO SOBRE MANEJO ESTRATÉGICO DA PASTAGEM, 2002, Viçosa, MG. Anais... Viçosa, MG: Universidade Federal de Viçosa, 2002. p.407-436.

ROSA, B.; REIS, R.A.; RESENDE, K.T. et al. Valor nutritivo do feno de Brachiaria decumbens Stapf. cv. basilisk submetido a tratamento com amônia anidra e uréia. Revista Brasileira de Zootecnia, v.27, n.4, p.815-822, 1998.

STATISTICAL ANALYSES SYSTEM - SAS. SAS/STAT user's guide. Version 6.4 ed., Cary: 1990. v.1, 943p.

SEIFFERT, N. F. Produção de feno com forrageiras de verão. Informe Agropecuário, v.6, n.64, p.8-11, 1988.

SHEN, H.S.; NI, D.B.; SUNDSTOL, F. Studies on untreated and urea-treated rice straw from three cultivation seasons: 1 . Physical and chemical measurements in straw and straw fractions. Animal Feed Science and Technology, v.73, p.243-261, 1998.

SILVA, D.J.; QUEIROZ, A.C. Análise de alimentos: métodos químicos e biológicos. Viçosa, MG: Universidade Federal de Viçosa, 2002. 235p.

SNIFFEN, C.J.; O'CONNOR, J.D.; VAN SOEST, P.J. et al. A net carbohydrate and protein system for evaluating cattle diets: 11. Carbohydrate and protein availability. Journal Animal Science, v.70, n.10, p.3562-3577, 1992.

SOUZA, A.L.; GARCIA, R.; PEREIRA, O.G. et al. Composição químico-bromatológica da casca de café tratada com amônia anidra e sulfeto de sódio. Revista Brasileira de Zootecnia, v.30, n.3 (suplemento1), p.983-991, 2001.

TILLEY, J.A.; TERRY, A.R. A two-stage technique for in vitro digestion of forage crops. Journal British Grassland Society, v.18, n.1, p.104-111, 1963.

Van SOEST, P.J. Nutritional ecology of the ruminant. Ithaca: Cornell University Press, 1994. 476p.

Van SOEST, P.J.; FERREIRA, A.M.; HARTLEY, R.D. Chemical properties of fibre in relation to nutritive quality of ammoniatreated forages. Animal Feed Science and Technology, v.10, n.2, p.156-164, 1984.

Van SOEST, P.J.; MASON, V.C. The influence of Maillard reaction upon the nutritive value of fibrous feeds. Animal Feed Science and Technology, v.32, n.1/3, p.45-53, 1991.

Recebido em: 05/08/04 Aceito em: 09/03/05 